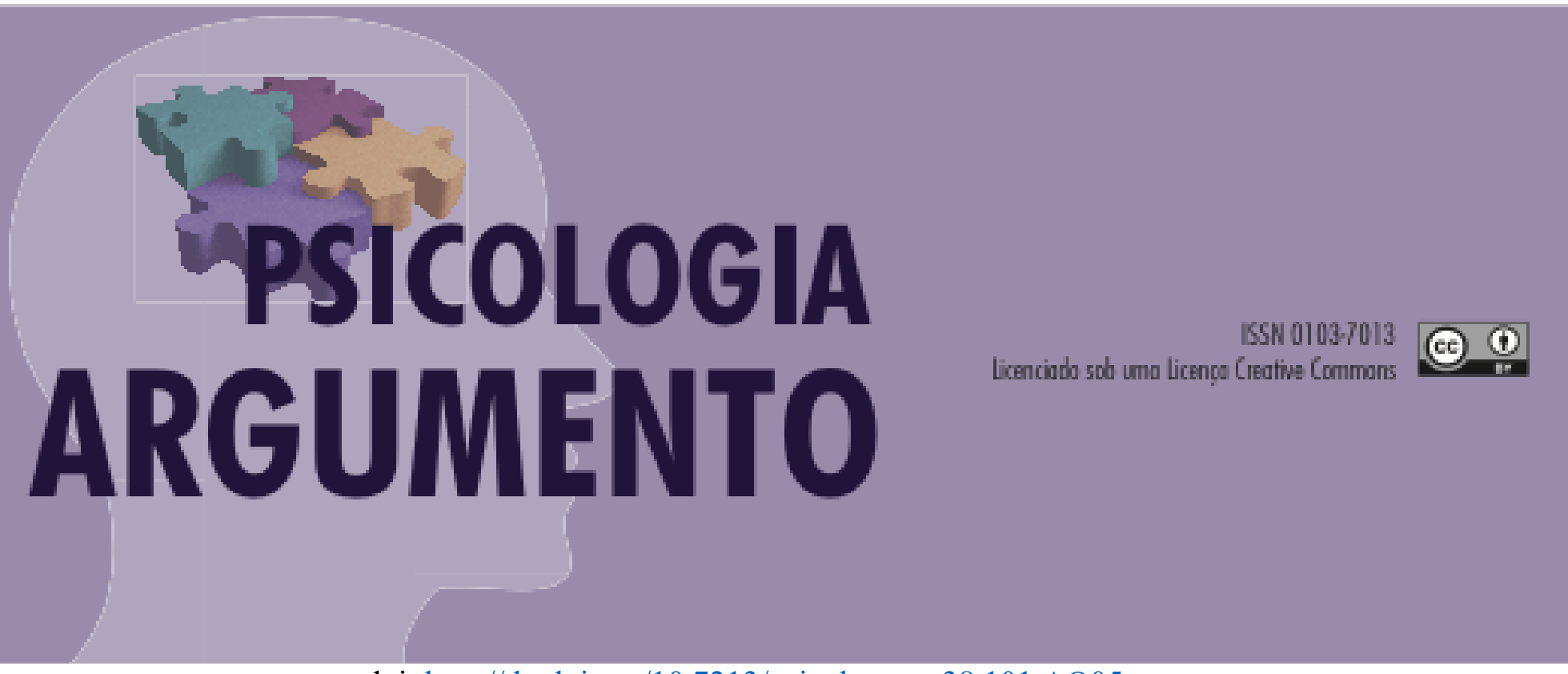

doi: http://dx.doi.org/10.7213/psicolargum.38.101.AO05

\title{
Representações Sociais de operadores do Direito e técnicos do Judiciário acerca do Depoimento Especial
}

\author{
Social Representations of Law Operators and Judicial Technicians about the Special \\ Testimony
}
Representaciones sociales de operadores legales y técnicos judiciales sobre el testimonio especial

\begin{abstract}
Andréia Isabel Giacomozzi
Profa. Dra. Departamento de Psicologia e PPGP - Programa de Pós Graduação em Psicologia Universidade Federal de Santa Catarina - UFSC agiacomozzi@hotmail.com, https://orcid.org/0000-0002-3172-5800

\section{Helena Berton Eidt}

Psicóloga Mestre em Psicologia - Coordenadoria Estadual da Infância e da Juventude do Tribunal de Justiça de Santa Catarina-CEIJ/TJSC, helenaberton@hotmail.com, https://orcid.org/0000-0002-9550-1072
\end{abstract}

Ana Maria Justo

Profa. Dra. Departamento de Psicologia - Universidade Federal de Santa CatarinaUFSC, justoanamaria@gmail.com,http://orcid.org/0000-0003-2056-3575

Jéssica Madeira Alves

Graduanda em Psicologia - Universidade Federal de Santa Catarina- UFSC madeirajessica@hotmail.com, https://orcid.org/0000-0001-9083-0654

\section{Resumo}

Com a entrada em vigor da Lei 13.431/2017, tornou-se obrigatória a implantação, pelos Tribunais de Justiça do Brasil, do Depoimento Especial - DE, procedimento de oitiva de crianças e adolescentes vítimas ou testemunhas de violência nos contextos policial e forense. Este estudo objetivou verificar as representações sociais de operadores do direito e técnicos acerca do DE. A 
pesquisa contou com 86 participantes, entre juízes, promotores de justiça, assistentes sociais e psicólogos com atuação junto ao Poder Judiciário Catarinense. Para coletar os dados foi utilizado um questionário auto-administrado. As questões fechadas foram analisadas com SPSS e as abertas e evocação de palavras com auxílio do software IRaMuTeQ. Observou-se que o principal profissional apontado pelos participantes para aplicar a técnica do DE foi o psicólogo e que as representações sociais do DE apontam para a proteção da criança, bem como para o cuidado e o respeito, com um ambiente adequado.

Palavras-chave: Representação social; depoimento especial; psicologia jurídica; psicologia do testemunho.

\section{Abstract}

With the entry into force of Law 13.431 / 2017, it became mandatory to implement the Special Testimony, procedure of hearing of children and adolescents victims or witnesses of violence in the police and forensic contexts, by the Courts of Justice of Brazil. This study aimed to verify the social representations of law operators and judicial technicians about the special testimony. The research had 86 participants, including judges, prosecutors, social workers and psychologists working with the Santa Catarina Judiciary. The technique used was the self-administered questionnaire. The closed questions were analyzed with SPSS and the open ones and evocation of words with the aid of IRaMuTeQ software. It was observed that the main professional appointed by the participants to apply the technique was the psychologist and that the social representations of special testimony pointed to the protection of the child, good as care and respect, with a suitable environment.

Keywords: social representation, special testimony; forensic psychology; testimonial psychology.

\section{Resumen}

Con la entrada en vigencia de la Ley 13.431 / 2017, se hizo obligatorio la implementación del Testimonio Especial, procedimiento de audiencia de niños y adolescentes víctimas o testigos de violencia en los contextos policiales y forenses, por parte de los Tribunales de Justicia de Brasil. Este estudio tuvo como objetivo verificar las representaciones sociales de los operadores legales y técnicos sobre el testimonio especial. La investigación contó con 86 participantes, incluidos jueces, fiscales, trabajadores sociales y psicólogos que trabajan con el Poder Judicial de Santa Catarina. Para recopilar los datos, se utilizó un cuestionario autoadministrado. Las preguntas cerradas se analizaron con SPSS y las preguntas abiertas y la evocación de palabras con la ayuda del software IRaMuTeQ. Se observó que el principal profesional designado por los participantes para aplicar la técnica ND era el psicólogo y que las representaciones sociales de la declaración especial apuntan a la protección del niño, así como al cuidado y respeto, con un ambiente apropiado.

Palabras clave: Representaciones sociales; testimonio especial; psicología legal; testimonio psicología

\section{Introdução}

O fenômeno da violência pode ser definido como a ameaça ou o uso real da força física ou poder, de forma intencional, contra si próprio, outra pessoa, grupo ou comunidade, que resulte ou possa resultar em lesão, morte, dano psíquico, prejuízo ao desenvolvimento ou privação (World Health Organization, 2002). Com relação às formas 
de apresentação, pode ser classificado como violência física, violência sexual, violência psicológica, e violência institucional (Brasil, 2017).

Especificamente sobre a violência sexual contra crianças e adolescentes, a Organização Mundial da Saúde (World Health Organization, 2006) a define como qualquer tipo de contato ou interação com alguém em estágio de desenvolvimento mais avançado, envolvendo atividade sexual para a qual ela não tem condições de compreender ou consentir, ou ainda que viola leis e tabus da sociedade. Assim, não é necessário haver contato físico entre a criança ou adolescente e o agressor, bastando que presencie conduta constrangedora, incluindo exposição do corpo em foto ou vídeo (Brasil, 2017). Em função da elevada incidência e dos graves prejuízos causados ao desenvolvimento cognitivo, afetivo e social das vítimas e suas famílias, esta forma de violência tem sido considerada um sério problema de saúde pública em diversos países, incluindo o Brasil (Habigzang \& Caminha, 2004; Veloso, Magalhães \& Cabral, 2017).

Apesar da complexidade de variáveis envolvidas na experiência de violência sexual, esta é considerada um importante fator de risco para o desenvolvimento de psicopatologias, das quais uma das mais citadas na literatura é o transtorno do estresse pós-traumático - TEPT (Habigzang, Borges, Dell'Aglio \& Koller, 2010; Torres, Maciel, Mendoza, Torres, \& Acosta, 2019). Há também referências ao desenvolvimento de quadros de depressão, transtornos de ansiedade, alimentares e dissociativos, enurese, encoprese, hiperatividade e déficit de atenção em crianças e adolescentes abusados sexualmente (Habigzang \& Caminha, 2004; Habigzang, Dala Corte, Hatzenberger, Stroeher \& Koller, 2008). As vítimas, além de apresentarem transtornos psicopatológicos, também podem desenvolver alterações comportamentais, cognitivas e emocionais (Habigzang \& Koller, 2006; Habigzang et al., 2008, Florentino, 2015; Macedo, Foschiera, Bordini, Habigzang \& Koller, 2019).

É importante destacar que essas alterações podem ocorrer como resposta à violência sofrida, mas não se configuram como sintomas característicos de vítimas de violência sexual. De acordo com Rovinski e Pelisoli (2019), não é possível identificar a violência sexual por meio de um conjunto específico de sintomas relacionados exclusivamente à sua ocorrência.

Assim, a palavra da criança torna-se a principal fonte de informações sobre o ocorrido, motivo pelo qual é bastante valorizada no contexto forense. Tanto a Lei $\mathrm{n}^{\mathrm{o}}$ 8.069, de 13 de julho de 1990, que dispõe sobre o Estatuto da Criança e do Adolescente 
- ECA (Brasil, 1990a) quanto o Decreto n 99.710, de 21 de novembro de 1990, que promulga a Convenção sobre os Direitos da Criança (Brasil, 1990b) enfatizam o direito da criança e/ou do adolescente de serem ouvidos. Em todo o processo judicial em que os interesses desses sujeitos estiverem envolvidos, deve ser oportunizada a sua oitiva, e a sua opinião deve ser devidamente considerada pela autoridade judiciária (Brasil, 1990a, 1990b). Entretanto, direito não se confunde com obrigação, o que faz com que as crianças possam exercer, ou não, este direito, não sendo obrigadas a depor (Pelisoli, Dobke \& Dell'Aglio, 2014).

As situações de violência sexual são de grande complexidade, o que exige habilidade técnica do profissional para se manter isento na avaliação das partes envolvidas (Rovinski, 2014). De acordo com Peixoto, Ribeiro e Alberto (2013), a entrevista forense é um momento fundamental na investigação criminal em que a criança assume o papel de testemunha, especialmente nos casos em que o discurso da criança é o único meio de prova. Entrevistar uma criança, segundo o autor, é uma tarefa exigente e desafiante, o que torna importante a especialização e formação contínua dos profissionais que atuam nesta área.

O fato da criança já ter passado por diversas entrevistas e profissionais antes de chegar à oitiva forense pode interferir na qualidade do seu relato. A suposta vítima pode, assim, apresentar um relato contaminado com informações que, muitas vezes, não condizem com a realidade da situação vivenciada (Perguer \& Stein, 2005; Rovinski, 2014; Stein, Perguer \& Feix, 2009). Apesar de tal constatação, o fato é que as crianças continuam a ser inquiridas várias vezes e por diferentes pessoas ao longo da trajetória do processo judicial, mesmo em processos em que existem sinais físicos do abuso sexual. Estudo aponta que meninas e meninos são ouvidos de oito a dez vezes ao longo de um processo judicial, precisando repetir - e reviver - a situação de violência sofrida para diversos órgãos de atendimento, investigação e responsabilização (Santos \& Gonçalves, 2009). Além da interferência negativa no relato, as inúmeras intervenções aumentam o risco de revitimização da criança, ou seja, de agravar o seu estado emocional, já prejudicado pela violência vivenciada (Peixoto et al., 2013).

Diante desse cenário, o Depoimento Especial - DE surge como recurso para a escuta de crianças e adolescentes vítimas ou testemunhas de violência no contexto forense. No Brasil, o Estado pioneiro foi o Rio Grande Do Sul, que, em 2003, adaptou a metodologia denominando-a de "Depoimento Sem Dano", com o intuito de retirar esses 
sujeitos do ambiente tradicional de audiência. De acordo com o então juiz da Vara da Infância e da Juventude de Porto Alegre/RS, Dr. José Antônio Daltoé Cezar, os principais objetivos do "Depoimento Sem Dano" eram: (a) a redução do dano à criança e ao adolescente vítima; (b) a garantia dos direitos, proteção e prevenção; e (c) melhoria da produção da prova produzida (Daltoé Cezar, 2007). A partir da experiência do Estado da região sul, outros também adotaram esse formato de escuta de crianças e adolescentes.

Posteriormente, em 2010, o Conselho Nacional de Justiça (CNJ, 2010) recomendou aos tribunais a criação de serviços especializados para essa escuta, por meio da Recomendação n. 33, de 23 de novembro de 2010, denominando o procedimento de Depoimento Especial. Após inúmeras discussões com a sociedade civil, órgãos públicos e organizações não governamentais, foi sancionada a Lei n. 13.431, de 4 de abril de 2017, que estabelece o sistema de garantia de direitos da criança e do adolescente vítima ou testemunha de violência e altera o ECA.

A referida legislação estabelece os procedimentos de escuta especializada (Art. 7) e de Depoimento Especial (Art. 8). A escuta especializada deve ser realizada por profissionais que atuam na rede de proteção à criança e ao adolescente, como órgãos da saúde, educação e assistência social, restringindo o relato à finalidade de cada serviço. $\mathrm{O}$ DE, por sua vez, é descrito (Brasil, 2017) como o procedimento de oitiva de criança ou adolescente, seja ela vítima ou testemunha de violência, perante autoridade policial ou judiciária, e deverá ser realizado por profissional especializado.

No DE, a entrevista com a vítima ou testemunha é realizada por meio de protocolos validados cientificamente em âmbito nacional e internacional. Tais protocolos possuem o objetivo de fornecer diretrizes que permitam ao profissional a obtenção de dados fidedignos por meio da condução da entrevista de maneira adequada (Rovinski \& Pelisoli, 2019). Pesquisas apontam que a utilização de protocolos minimiza as falhas comumente encontradas em situações de entrevista com vítimas ou testemunhas de violência, além de aumentarem o número e a qualidade das informações relatadas (Stein, Perguer \& Feix, 2009). Os principais protocolos estudados e utilizados no DE são a Entrevista Cognitiva e o National Institute of Child and Human Development (NICHD) (Rovinski \& Pelisoli, 2019). O sistema PEACE, apesar de menos conhecido, é utilizado em Santa Catarina, Estado onde foi realizada a presente pesquisa, juntamente com os outros dois protocolos citados. 
Em Santa Catarina, a implantação do DE enquanto projeto institucional deu-se a partir da entrada em vigor da Lei $\mathrm{n}^{\circ}$ 13.431, de 4 de abril de 2017 (Tribunal de Justiça de Santa Catarina, 2018). Trata-se de um procedimento novo, de modo que se considerou importante conhecer as representações sociais (RS) acerca da referida metodologia pelos operadores do Direito e técnicos do Judiciário, antes da capacitação dos mesmos sobre a temática. As RS são construídas de modo a tornar familiar o desconhecido (Moscovici, 2012), e seu estudo favorece a compreensão dos aspectos psicossociais que estão envolvidos na atribuição de significado aos fenômenos relevantes a um grupo.

Segundo Moscovici (2012), a Teoria das Representações Sociais (TRS) - que fundamenta essa pesquisa, compreende-se em um conjunto de conceitos, ideias, afirmações e explicações sobre a realidade, originadas na vida cotidiana, durante a interação entre os grupos, a qual é refletida nas formas da sociedade adquirir conhecimento. É impossível conhecer sem representar, sendo as RS fenômenos subjetivos, intersubjetivos, intergrupais e objetivos (Jodelet, 2017). Para Wagner (2015), RS é um conceito que é estruturado mentalmente sobre determinado fato social, que é partilhado com indivíduos de um determinado grupo. Estudar as RS portanto, é identificar as visões de mundo que os indivíduos possuem, que refletem nas representações do objeto e atuam como agentes de influência nas práticas dos sujeitos em uma produção de sentidos (Jodelet, 2017).

As RS são produzidas e partilhadas pelas pessoas com o objetivo de construir uma realidade comum aos membros de um grupo. Guareschi e Roso (2014), afirmam que na sociedade existe um "mundo psíquico", que seriam as representações que trazem sentido aos indivíduos e os mantêm unidos. Além disso, nos guiam para definir, nomear e interpretar diferentes aspectos da realidade, tomar decisões e posicionamentos frente a eles (Jodelet, 2017). A abordagem estrutural das RS acrescenta que estas se organizam em torno de um núcleo central, parte mais estável da representação e que orienta o sentido dos demais elementos que compõem um sistema periférico (Moliner, 2016).

Moscovici (2012) expõe que as RS têm como função permitir às pessoas orientarem-se em seu meio social e construir uma rede de significados que favoreçam a comunicação sem ambiguidade. Em conformidade, Jodelet (2017) e Wagner (2015) explicam que as RS procuram esclarecer aspectos da realidade, norteiam práticas sociais, explicam ações e atitudes, orientam e organizam as condutas e as comunicações. Nesse sentido, o presente estudo teve como objetivo descrever as RS relativas ao DE, bem como 
conhecer a opinião dos operadores do Direito e técnicos do Judiciário sobre qual seria o profissional mais indicado a realizar este tipo de intervenção. Para o estudo das RS, optou-se mais especificamente pelo recurso disponibilizado pela abordagem estrutural da TRS (Abric, 2003), a partir de tarefa de evocação livre de palavras. Essa é uma técnica amplamente utilizada dentro da TRS devido à relativa simplicidade para coleta de dados e capacidade de atingir resultados pertinentes para estudos com finalidade exploratória (Wachelke \& Wolter, 2011).

\section{Objetivos}

Descrever as RS relativas ao $\mathrm{DE}$, bem como conhecer a opinião dos operadores do Direito e técnicos do Judiciário sobre qual seria o profissional mais indicado a realizar este tipo de intervenção.

\section{Método}

Trata-se de um estudo de natureza exploratória e descritiva, com abordagem qualitativa e corte transversal. Participaram 86 operadores do Direito e técnicos do Poder Judiciário (49 mulheres e 37 homens), diretamente ligados à aplicação da metodologia do DE no Judiciário Catarinense já que, após curso de capacitação que sucedeu a coleta, passariam a aplicar a metodologia do DE nos fóruns das comarcas. A média da idade dos participantes foi de 38,7 anos $(\mathrm{DP}=6,2)$, variando de 27 a 53 anos. Sobre a escolaridade, todos os participantes relataram possuir curso superior, sendo que 26 realizaram especializações, dez fizeram mestrado e cinco cursaram doutorado em sua área de atuação. Quanto ao tipo de cargo exercido, 49 participantes declararam ocupar o cargo de juiz, 30 o de promotor de justiça, 4 de assistente social, 2 de psicólogo.

$\mathrm{O}$ instrumento utilizado para coleta de dados foi um questionário auto-aplicado desenvolvido exclusivamente para esse estudo, composto por: (1) teste de evocação livre; (2) questão aberta para justificar a escolha das duas palavras que o participante considerasse mais importantes; (3) pergunta sobre qual(is) deveriam ser os profissionais a realizar os procedimentos relacionados ao DE; (4) fontes de informação sobre o DE; além de questões de caracterização. A aplicação ocorreu antes do início de um curso de capacitação sobre a temática, a fim de investigar as RS dos participantes, conhecimentos 
sobre a temática e fatores associados, antes da qualificação a respeito do DE. O estudo foi aprovado pelo Comitê de Ética da Universidade (CAAE n. 84656218.7.0000.0121). Todos os procedimentos respeitaram as orientações éticas relativas às pesquisas envolvendo seres humanos.

Para a análise dos dados quantitativos foram realizadas análises estatísticas descritivas e de frequência com o auxílio do software SPSS. Para analisar o teste de evocações livres e as questões abertas, foram utilizados diferentes procedimentos de análise lexical, com o auxílio do software IRaMuTeQ. Realizou-se análise prototípica (Wachelke \& Wolter, 2011), a partir da frequência e ordem média de evocação das palavras, análise de similitude e nuvem de palavras (Justo \& Camargo, 2014).

\section{Resultados}

A identificação das RS do DE ocorreu a partir da análise lexicográfica das palavras evocadas com auxílio do software IRaMuTeQ. Constatou-se dentre as 429 evocações, 171 palavras distintas. Destas, 105 tiveram frequência igual a um (hapax) sendo excluídas da análise. Restaram, desse modo, 65 palavras analisáveis, cuja frequência média de ocorrência foi igual a cinco. Realizou-se uma análise prototípica (Wachelke \& Wolter, 2011), considerando-se a frequência de ocorrência das palavras e sua ordem média de evocação, a partir das palavras que obtiveram frequência igual ou maior que cinco, de modo a identificar a estrutura da representação. Os resultados encontram-se sintetizados na Tabela 1 .

Observa-se que, no quadrante superior esquerdo, destacam-se os elementos "proteção," criança", "respeito", "constrangimento", os quais tiveram alta frequência e baixa ordem de evocação - ou seja, elementos que mais apareceram e que foram prontamente evocados pelos participantes. Tais elementos possuem tendência de centralidade, possivelmente constituindo o núcleo central da representação de Depoimento Especial para este grupo de participantes, denotando o DE como uma técnica favorável ao respeito e proteção da criança, mas com a necessidade de evitar-se um momento de possível constrangimento. 
Tabela 1

Análise Prototípica do teste de evocações livres sobre Depoimento Especial

\begin{tabular}{|c|c|c|c|c|c|c|}
\hline & \multicolumn{3}{|c|}{ Ord. Méd. Evoc $<2,6$} & \multicolumn{3}{|c|}{ Ord. Méd. Evoc $<2,6$} \\
\hline & \multicolumn{3}{|c|}{ Zona do Núcleo } & \multicolumn{3}{|c|}{ Primeira Periferia } \\
\hline & Palavra & Freq. & $O M E$ & Palavra & Freq. & $O M E$ \\
\hline \multirow{4}{*}{ Freq $>12$} & Proteção & 36 & 1,9 & Cuidado & 18 & 2,8 \\
\hline & Criança & 27 & 2,1 & Verdade & 13 & 3,4 \\
\hline & Respeito & 14 & 2,6 & & & \\
\hline & Constrangimento & 13 & 2,5 & & & \\
\hline \multirow{10}{*}{ Freq $<12$} & \multicolumn{3}{|c|}{ Zona de Contraste } & \multicolumn{3}{|c|}{ Segunda Periferia } \\
\hline & Palavra & Freq. & $O M E$ & Palavra & Freq. & $O M E$ \\
\hline & Acolhimento & 9 & 2,2 & Prova & 9 & 4,0 \\
\hline & Sigilo & 5 & 2,0 & Segurança & 8 & 3,5 \\
\hline & Dano & 5 & 2,0 & Dificuldade & 8 & 3,5 \\
\hline & & & & Empatia & 8 & 3,0 \\
\hline & & & & Trauma & 7 & 2,9 \\
\hline & & & & Revitimização & 7 & 3,0 \\
\hline & & & & Violência & 5 & 3,0 \\
\hline & & & & Psicologia & 5 & 4,0 \\
\hline
\end{tabular}

A zona da primeira periferia (quadrante superior direito) inclui as respostas com alta frequência, mas que não foram evocadas com prontidão. Nesse caso, encontram-se os elementos "cuidado" e "verdade". Para os participantes, parece importante cuidar deste momento de depoimento da criança ou adolescente, que permitirá a aproximação da verdade dos fatos. No quadrante inferior esquerdo vemos palavras que tiveram frequência abaixo da média de corte, mas que foram evocadas prontamente pelos participantes. Encontram-se palavras como "acolhimento", "sigilo" e "dano", formando o que se chama de zona de contraste. $\mathrm{O}$ cuidado com os dados relatados pela criança ou adolescente em seu depoimento, bem como com o seu bem-estar durante o procedimento, mostram-se como aspectos valiosos para os profissionais participantes.

Na segunda periferia, no quadrante inferior direito da Tabela 1, encontramos as palavras: "prova”, "segurança”, “dificuldade”, “empatia”, "trauma”, "revitimização", "violência" e "psicologia". Elas tiveram frequência de evocação inferiores ao ponto de corte, referenciando elementos menos salientes, provavelmente periféricos na estrutura da representação do grupo social. Contudo, trazem aspectos mais particularizados dos participantes que apontam para a Psicologia como a profissão adequada para a realização de tal procedimento.

A justificativa dos participantes à escolha das palavras que estes consideravam mais importantes foi submetida a uma análise de similitude, de modo a explorar seu 
conteúdo. As palavras localizam-se nos vértices, sendo o tamanho da fonte proporcional à frequência de ocorrência das palavras (quanto maior a fonte, maior a frequência). $\mathrm{O}$ valor das arestas indica o índice de coocorrência entre as palavras.

A Figura 1 permite identificar que os elementos "vítima" e "criança" são centrais às justificativas, sendo que o segundo tem forte coocorrência (27) com a palavra "adolescente", que tivera frequência baixa no teste de evocação livre. "Proteger", "evitar revitimização", "dano" e "maior sofrimento" aparecem no eixo superior direito do gráfico.

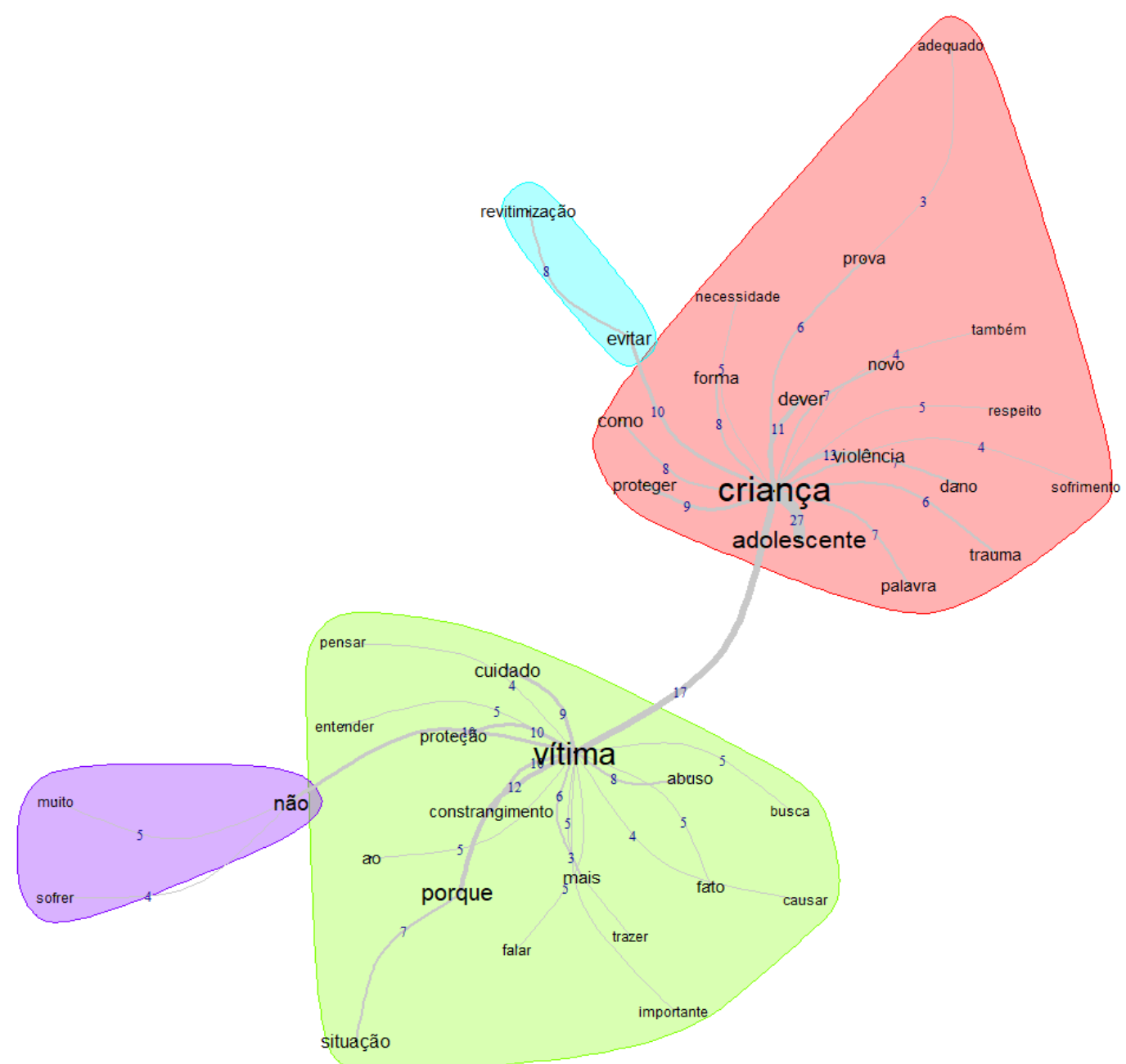

Figura 1. Análise de similitude das justificativas à escolha das palavras evocadas.

O eixo inferior direito, por sua vez, relaciona a vítima a elementos como "cuidado", "constrangimento", "proteção" e "entendimento". Além disso, o elemento "não", com frequência alta, ligado a "muito" e a "sofrer", evidencia a ideia do DE como uma forma de reduzir os danos. 
Questionados sobre qual(is) deveriam ser os profissionais a realizar os procedimentos relacionados ao $\mathrm{DE}, 48$ participantes responderam que deveria ser o psicólogo o profissional responsável pela coleta do depoimento. Este profissional foi o mais citado, seguido pelo assistente social $(n=17)$, pela equipe multidisciplinar $(n=5)$ e psicólogo e algum profissional do Direito $(n=5)$. Como as respostas ao questionário eram abertas, estas foram sintetizadas em uma nuvem de palavras (Figura 2).

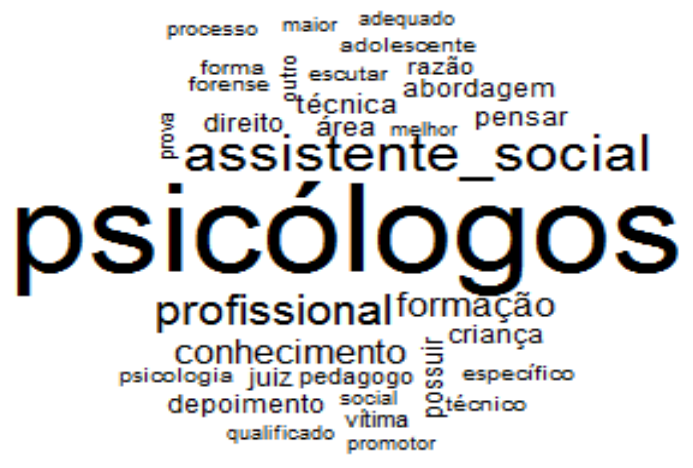

Figura 2. Nuvem de palavras

A nuvem é uma representação que possibilita identificar graficamente a saliência dos elementos principais, sendo que o tamanho e centralidade das palavras são diretamente proporcionais à sua frequência. Fica evidente que a maior parte dos participantes destacou o psicólogo como o mais preparado para a realização do DE, por ser um profissional qualificado e comprometido com o bem-estar da criança e do adolescente, como é possível observar na seguinte resposta: “O Psicólogo, tem formação para compreender os traumas e danos, e deles poder extrair as informações necessárias ao litígio. Juiz e operadores de direito não possuem informação para lidar com esse tipo de situação de maneira adequada" (Juíza, 33 anos, ensino superior).

Por fim, questionou-se os profissionais quais seriam as principais fontes de conhecimento deles sobre DE. Foram citadas mais de duas fontes por todos os participantes e a síntese dos resultados encontra-se na Figura 4. 


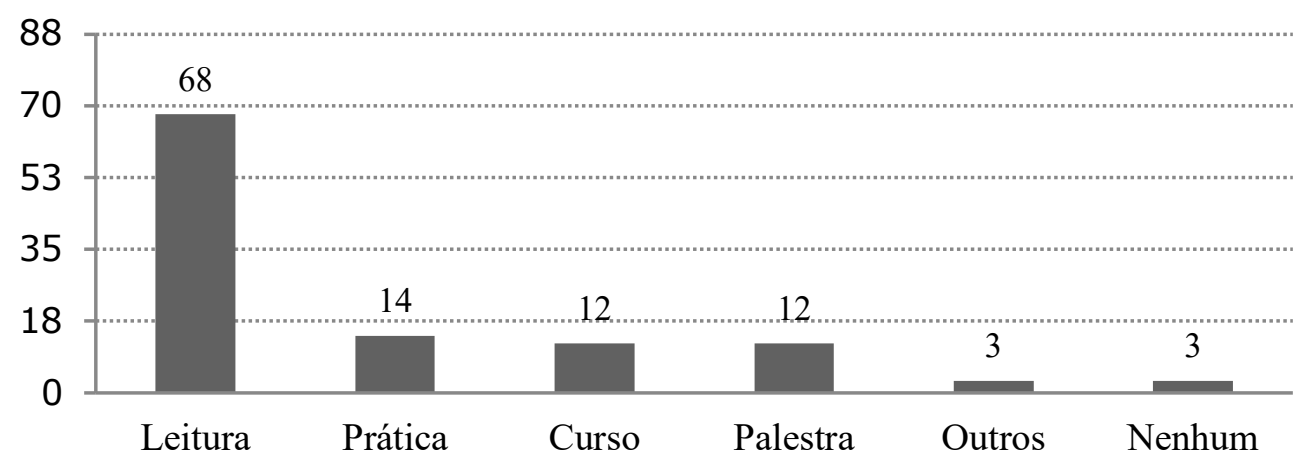

Tipo de fontes citadas

Figura 4. Fontes de conhecimento sobre o Depoimento Especial.

A fonte largamente mais evocada foi leitura, seguida do conhecimento adquirido a partir da prática, cursos e palestras. Dentro da fonte leitura, foi possível identificar os meios utilizados pelos profissionais sendo estes: artigos, leis, livros.

\section{Discussão}

A partir da teoria do núcleo central (Abric, 1998), uma RS constitui-se como um conjunto organizado e estruturado de informações, crenças, opiniões e atitudes, composta de dois subsistemas - o central e o periférico, em que cada um tem papel especifico e complementar. Ao explorar a RS do DE, o estudo identificou o elemento "proteção" como o mais frequente, seguido de "criança" que é o público alvo da metodologia. Tais elementos, com frequência em grande destaque e baixa ordem média de evocação, a partir da abordagem estrutural (Abric, 1998) configuram o provável núcleo central da RS acerca do DE entre o grupo de participantes (Wachelke \& Wolter, 2011). Este núcleo tem uma função valorativa e acaba por orientar o sentido dos demais elementos representacionais (Sá, 1996).

Sendo assim, a partir de uma leitura dos prováveis elementos periféricos da RS, considera-se que a proteção da criança pelo DE envolve a promoção de um espaço de acolhimento, respeito, cuidado e, ainda que provoque possível constrangimento, pode minimizar os danos decorrentes da necessidade de tomar repetidas vezes o depoimento da criança sobre a violência sofrida. Também compõem a periferia da RS elementos que estão diretamente ligados ao fato investigado, tais como verdade e prova, mas que nesse contexto podem ser tratadas com sigilo, segurança e empatia, elementos pragmáticos que 
revelam uma dimensão ética da atuação nesta metodologia, de modo a reiterar as funções de atualização e contextualização da RS (Abric, 1998).

A análise da justificativa às evocações mais importantes trouxe em evidência os adolescentes, que pouco apareceram na questão anterior, mas que também fazem parte do público alvo do DE. Além disso, a presença do advérbio "não" revela a ideia da proteção da vítima, a partir da evitação de condições que reiterem seu sofrimento. Tal representação vai ao encontro dos direitos fundamentais da criança e do adolescente, previstas na Lei no 13.431, de 4 de abril de 2017 (Brasil, 2017), bem como das técnicas de entrevista adotadas pelos protocolos utilizados no DE, que incluem o acolhimento da vítima ou testemunha, evitando práticas iatrogênicas.

Moscovici (2012) aponta que uma das dimensões que compõem a RS é a informação acerca do objeto em questão. Especialmente por tratar-se de um objeto novo, até mesmo para os profissionais da área do Direito, considera-se importante conhecer quais são as fontes de informação destes a respeito do tema. Na presente pesquisa, destacam-se as leituras como fontes de informação, embora não tenha havido um consenso sobre o tipo de leituras.

Ao distinguir sobre representações baseadas em conhecimento e representações baseadas em crenças, Palmonari \& Cerrato (2011) consideram que as RS sempre envolvem tanto conhecimentos quanto crenças, podendo estar mais orientadas por um ou outro estilo de pensamento. Salienta-se, conforme Jovchelovitch (2011) que as RS são compostas a partir de uma combinação de fontes de informações diversas, num fenômeno denominado polifasia cognitiva. Nesse sentido, as RS compartilhadas pelos profissionais do Direito mesclam os conhecimentos próprios de sua especialidade técnica, com demais crenças, valores, estereótipos, não necessariamente atrelados ao seu saber profisssional.

Apesar da existência e reconhecimento da prática do DE em diversos países dos cinco continentes (Santos \& Gonçalves, 2009), no Brasil, não há consenso entre os profissionais sobre quem deve realizá-lo, o que gera constantes e acalorados debates, especialmente nas áreas da Psicologia, Serviço Social e Direito. Os Conselhos Federais de Psicologia (CFP) e Serviço Social (CFESS) posicionaram-se de forma contrária à participação de psicólogos e assistentes sociais na entrevista de crianças e adolescentes na modalidade de Depoimento Especial. Em 2009, o CFESS emitiu a Resolução n ${ }^{\circ}$ 554/2009, e em 2010, o CFP lançou a Resolução nº 010/2010, impedindo os profissionais de ambas as áreas de empregarem a técnica, a qual consideram como inquirição de 
crianças. Contudo, a primeira fora suspensa pelo Poder Judiciário e a segunda revogada pelo CFP em março de 2020, o que torna possível a participação de psicólogos e assistentes sociais no procedimento.

Um dado em destaque neste estudo é a forte referência ao profissional da Psicologia como aquele indicado para proceder com o DE. Vale reiterar que, dentre os 86 participantes do estudo, apenas dois são psicólogos. Nesse sentido, levantam-se dois elementos para discussão, sendo que estes podem estar diretamente relacionados: (1) a indicação dos profissionais participantes de que eles mesmos não seriam os profissionais adequados para realizar esse tipo de intervenção, e (2) a falta de qualificação destes profissionais para atuarem junto ao DE.

Em relação ao primeiro, a análise das RS sobre o DE aponta que este envolve condições difíceis de manejar. A comunicação da situação de violência envolve sofrimento, constrangimento e até mesmo trauma, segundo os operadores do Direito e técnicos do judiciário participantes do estudo. Esta concepção negativa acaba por distanciar os profissionais das ações relativas ao DE. Trata-se de uma situação que ainda pode ser desconfortável aos profissionais, e, portanto, seria mais indicada aos psicólogos, os quais estariam mais "habilitados" a este tipo de prática.

Um outro fato a considerar é que possivelmente os participantes sentem-se despreparados para lidar com a delicadeza deste tipo de procedimento. Vale lembrar que segundo a legislação, todavia, o DE deverá ser realizado por profissional especializado (Brasil, 2017). Ou seja, não é uma atribuição exclusiva de psicólogos e assistentes sociais, podendo ser realizada por outros profissionais, desde que devidamente capacitados. E nesse ínterim, considera-se que os profissionais comumente tem qualificação insuficiente para o manejo do procedimento. Assim, o DE acaba sendo diretamente relacionado à Psicologia, que historicamente é associada a intervenções que envolvam as diversas formas de sofrimento psíquico.

Em pesquisa realizada por Santos e Gonçalves (2009), países como Argentina, Chile, Equador, Paraguai e Peru definiram o psicólogo como o único profissional capaz de conduzir a oitiva de crianças e adolescentes para a produção de provas em processos judiciais, o que demonstra a relação da Psicologia com essa área de atuação em diversos contextos, além do Brasil. Já em estudo realizado por Pelisoli e Dell'Aglio (2016) junto a profissionais do Poder Judiciário do Rio Grande do Sul, Estado com vasta experiência na realização do $\mathrm{DE}$, os resultados apontaram o treinamento para a coleta do depoimento 
como mais importante que a graduação do profissional, apesar de alguns participantes mostrarem predileção pelo psicólogo enquanto entrevistador.

De acordo com Pelisoli et al. (2014), os psicólogos desenvolvem, ao longo da sua formação, conhecimentos sobre desenvolvimento humano, acolhimento, dinâmicas da violência e avaliação psicológica, que se mostram diretamente relacionados com a proteção dos direitos da criança e do adolescente em situação de violência e com as bases da formação técnica para a coleta do DE. Assim, os operadores do Direito acabam necessitando e solicitando a atuação desses profissionais nos casos em que o conhecimento jurídico não é suficiente para o seu entendimento e resolução, como os que envolvem abuso sexual.

Uma das dificuldades dos operadores do Direito pode ser a de entrevistar crianças e adolescentes, o que é menos comum em sua prática cotidiana. Pelisoli et al. (2014) afirmam que o ato de ouvir crianças vítimas de abuso sexual é uma tarefa de grande complexidade, tendo em vista o pouco conhecimento da dinâmica da violência e o despreparo emocional dos profissionais operadores do Direito e técnicos do Judiciário.

Este despreparo tem graves implicações, uma vez que as dificuldades e inadequações acerca do modo de realização do procedimento podem acabar por dificultar o cumprimento do objetivo do depoimento, que seria a coleta do relato do fato (Pelisoli et al., 2014), o que justifica a capacitação dos profissionais que realizam o DE. É importante destacar que os participantes do presente estudo ainda não haviam recebido qualquer capacitação por parte do Tribunal de Justiça, mas que esta é obrigatória a todos os profissionais que participam do procedimento, técnicos e juízes (Brasil, 2017). A metodologia do DE necessita da interdisciplinaridade, do diálogo entre os saberes, a fim de possibilitar a construção de estratégias para garantir o direito das crianças e adolescentes em situações de violência, ao mesmo tempo em que é possibilitada a produção da prova. Uma das alternativas para que isso ocorra é a estruturação de espaços de formação, debates e trocas entre os profissionais, possibilitando a conscientização e sensibilização para esta modalidade de trabalho.

\section{Considerações finais}

A presente pesquisa buscou entender as RS dos operadores do Direito e dos servidores do Poder Judiciário catarinense acerca do Depoimento Especial - DE, 
metodologia para a escuta de crianças e adolescentes vítimas ou testemunhas de violência implementada no Estado recentemente, a partir da entrada em vigor da Lei ${ }^{\circ} 13.431$, de 4 de abril de 2017. Os participantes foram questionados no momento anterior à capacitação sobre a temática, o que permitiu a exposição das ideias e opiniões a respeito da metodologia, antes da obtenção de informações acerca do projeto institucional e das técnicas de entrevista utilizadas no Depoimento Especial.

Os profissionais participantes - juízes, promotores de justiça, psicólogos e assistentes sociais - apontaram como possível elemento central das RS do DE a proteção da criança, destacando esse aspecto em detrimento de questões processuais, como a produção de provas. É importante ressaltar que a maioria dos participantes atua como profissional da área do Direito, o que demonstra a mudança de perspectiva acerca dos processos judiciais que envolvem crianças e adolescentes, priorizando a sua proteção e bem-estar. Tal resultado contrasta com as críticas dirigidas ao DE, de que serviria exclusivamente ao aumento do número de condenações e que violaria direitos das vítimas e dos investigados.

Entende-se que a proteção das crianças e adolescentes vítimas ou testemunhas de violência também está relacionada com a responsabilização do agressor, ou com a absolvição do investigado que não cometeu crime. Contudo, para que exista um equilíbrio entre as necessidades da criança e as necessidades do sistema de Justiça, algumas condições são fundamentais, como a escolha da técnica de entrevista e o ambiente onde o procedimento será realizado, aspectos previstos no $\mathrm{DE}$.

Os participantes ainda demonstraram a compreensão de que o psicólogo é o profissional mais indicado para a realização do Depoimento Especial, por sua formação e prática na entrevista com crianças. Acredita-se que, com a capacitação de magistrados e servidores e com a prática do Depoimento Especial, essa crença ceda espaço à confiança na capacidade de outras categorias profissionais de realizarem o procedimento, a exemplo do Serviço Social, uma vez que não se trata de procedimento exclusivo a qualquer especialidade.

Uma das limitações da pesquisa refere-se ao fato de a coleta de dados envolver apenas profissionais do estado de Santa Catarina. Considera-se que a ampliação do campo a todo o território nacional poderia contemplar as diversidades regionais. Ademais, o uso da abordagem estrutural para o estudo de um novo objeto de RS pode trazer indicadores, mas não permite inferências precisas do núcleo e da periferia da representação. Pondera- 
se, todavia, que o estudo de uma RS social em processo de formação poderá subsidiar outras pesquisas, para aprofundamento. Além disso, novos estudos sobre a percepção dos envolvidos sobre o DE, tanto profissionais quanto crianças, adolescente e familiares, podem auxiliar na compreensão das dificuldades e no aprimoramento da técnica.

\section{Referências}

American Psychological Association. (2012). Manual de publicação da American Psychological Association (6a ed., D. Bueno, trad.). Porto Alegre, RS: Penso.

Abric, J-C. (1998). A abordagem estrutural das representações sociais. In A. S. P. Moreira \& D. C. de Oliveira (Orgs.), Estudos interdisciplinares de representação social. (pp.27-38). Goiânia: AB.

Brasil (1990a). Lei 8.069, de 13 de julho de 1990. Brasília: Senado Federal.

Brasil (1990b). Decreto 99.710, de 21 de novembro de 1990. Brasília: Senado Federal.

Brasil (2017). Lei 13.431, de 4 de julho de 2017. Brasília: Senado Federal. http://www.planalto.gov.br/ccivil_03/_ato2015-2018/2017/Lei/L13431.htm

Conselho Nacional de Justiça (2010). Recomendação n. 33, de 23 de novembro de 2010. Brasília.

Daltoé Cezar, J. A. (2007). Depoimento sem dano: Uma alternativa para inquirir crianças e adolescentes nos processos judiciais. Porto Alegre, RS: Livraria do Advogado.

Florentino, B. R. B. (2015). As possíveis consequências do abuso sexual praticado contra crianças e adolescentes. Fractal: Revista de Psicologia,27(2), 139144. https://dx.doi.org/10.1590/1984-0292/805

Guareschi, P. A., \& Roso, A. (2014). Teoria das Representações Sociais - Sua história e seu potencial crítico e transformador. In E. M. Q. O, Chamon, P. A., Guareschi, \& P. H. F., Campos (Org.), Textos e Debates em Representação Social. Porto Alegre: ABRAPSO.

Habigzang, L. F. \& Caminha, R. M. (2004). Abuso sexual contra crianças e adolescentes: Conceituação e intervenção clínica. São Paulo: Casa do Psicólogo.

Habigzang, L. F., \& Koller, S. H. (2006). Terapia cognitivo-comportamental e promoção de resiliência para meninas vítimas de abuso sexual intrafamiliar. In D. D. Dell'aglio, S. H. Koller, \& M. A. M. Yunes, (Eds.), Resiliência e psicologia positiva: Interfaces do risco à proteção (pp. 233-258). São Paulo, SP: Casa do Psicólogo. 
Habigzang, L. F., Dala Corte, F., Hatzenberger, R., Stroeher, F. \& Koller, S. H. (2008). Avaliação Psicológica em Casos de Abuso Sexual na Infância e Adolescência. Psicologia: Reflexão e Crítica, 21(2), 338-344. http://dx.doi.org/10.1590/S010279722008000200021

Habigzang, L. F., Borges, J. L., Dell'Aglio, D. D., \& Koller, S. H. (2010). Caracterização dos sintomas do Transtorno de Estresse Pós-Traumático (TEPT) em meninas vítimas de abuso sexual. Psicologia Clínica, 22(2), 27-44. https://doi.org/10.1590/S0103$\underline{56652010000200003}$

Macedo, D. M.; Foschiera, L. N., Bordini, T. C. P. Habigzang, L. F. \& Koller, S. H. (2019). Revisão sistemática de estudos sobre registros de violência contra crianças e adolescentes no Brasil. Ciência \& Saúde Coletiva, 24(2), 487-496. https://dx.doi.org/10.1590/1413-81232018242.34132016

Jodelet, D. (2017). Representações sociais e mundos de vida. Curitiba: PUCPRess.

Jovchelovitch, S. (2011) Representações sociais e polifasia cognitiva: notas sobre a pluralidade e sabedoria da Razão em Psicanálise, sua imagem e seu público. In A. M. O. Almeida, M. F. Souza \& Z. A. Trindade (Eds.), Teoria das representações sociais - 50 anos (159-176). TechnoPolitik Editora, Rio de Janeiro.

Justo, A. M. \& Camargo, B. V. (2014). Estudos qualitativos e o uso de Softwares para análiseslexicais. Em: Novikoff, C.; Santos, S. R. M. \& Mithidieri, O. B.(Orgs.) Caderno de artigos: XSIAT \& II Serpro (2014: Duque de Caxias, RJ) (p. 37-54). Duque de Caxias: Universidade do Grande Rio "Professor José de Souza Herdy" UNIGRANRIO. :https://lageres.wordpress.com/

Moliner, P. (2016). From Central Core Theory to Matrix NucleusTheory. Papers on Social Representations $26 \quad$ (2), 3.1-3.12 http://psr.iscteiul.pt/index.php/PSR/article/view/39/6

Moscovici, S. (2012). A psicanálise, sua imagem e seu público. Petrópolis, RJ: Vozes.

Palmonari, A., \& Cerrato, J. (2011). Representações sociais e psicologia social. In A. M. O. Almeida, M. F. S. Santos \& Z. A. Trindade (Orgs.), Teoria das representações sociais: 50 anos (pp. 305-332). Brasília, DF: Technopolitik Gulbenkian.

Peixoto, C. C. E., Ribeiro, C. \& Alberto, I. (2013). O Protocolo de Entrevista Forense do NICHD: contributo na obtenção do testemunho da criança no contexto português. Revista do Ministério Público. 134, 149-18. 
Pelisoli, C., Dobke, V. \& Dell'Aglio, D. D. (2014). Depoimento Especial: Para além do embate e pela proteção das crianças e adolescentes vítimas de violência sexual. Temas em Psicologia, 22(1), 25-38. http://dx.doi.org/10.9788/TP2014.1-03

Pelisoli, C. \& Dell'Aglio, D. D. (2016). A humanização do sistema de justiça por meio do Depoimento Especial: Experiências e desafios. Psico-USF, 21(2), 409-421. https://doi.org/10.1590/1413-82712016210216

Rovinski, S. L. R. (2014). Fundamentos da Perícia Psicológica Forense. $3^{\mathrm{a}}$ ed. São Paulo: Vetor.

Rovinski, S. L. R. \& Pelisoli, C. (2019). Violência sexual contra crianças e adolescentes: testemunho e avaliação psicológica. São Paulo: Vetor.

Sá, C. P. (1996). Representações sociais: teoria e pesquisa do núcleo central. Temas em Psicologia, $\quad 4(3), \quad$ 19-33. http://pepsic.bvsalud.org/scielo.php?script=sci_arttext\&pid=S1413$\underline{389 X 1996000300002}$

Santos, B. R., \& Gonçalves, I. B. (2009). Depoimento sem medo: Culturas e práticas não revitimizantes - Uma cartografia das experiências de tomada de depoimento especial de crianças e adolescentes. São Paulo, SP: Childhood Brasil.

Stein, L. M.; Pergher, G. K., \& Feix, L. F. (2009). Desafios da oitiva de crianças no âmbito forense. Brasília-DF: Secretaria Especial dos Direitos Humanos da Presidência da República/Subsecretaria de Promoção dos Direitos da Criança e do Adolescente Programa Nacional de Enfrentamento da Violência Sexual contra Crianças e Adolescentes. Childhood Brasil.

Torres, L.C.; Maciel, C. G.G.; Mendoza, A. L.G.; Torres, L.S. \& Acosta, L. B. (2019). Malestar Psicológico en víctimas de violencia sexual, intrafamiliar y del conflicto armado. Tempus $\quad$ Psicológico, $\quad 3(1), \quad 81-102$. https://doi.org/10.30554/tempuspsi.3.1.2878.2020

Tribunal de Justiça de Santa Catarina. (2018). Resolução Conjunta do Gabinete da Presidência e da Corregedoria Geral da Justiça do Tribunal de Justiça de Santa Catarina, n.8, de 24 de setembro de 2018. Dispõe sobre o depoimento especial de crianças e adolescentes vítimas ou testemunhas de violência realizado no âmbito do Poder Judiciário do Estado de Santa Catarina e dá outras providências. http://busca.tjsc.jus.br 
Veloso, M. M. X., Magalhães, C. M. C. \& Cabral, I. R. (2017). Identificação e notificação de violência contra crianças e adolescentes: limites e possibilidades de atuação de profissionais de saúde. Mudanças - Psicologia da Saúde, 25 (1), 1- 8. http://dx.doi.org/10.15603/2176-1019/mud.v25n1p1-8

Wachelke, J. F. R., \& Wolter, R. P. (2011). Critérios de construção e relato da análise prototípica para representações sociais. Psicologia: Teoria e Pesquisa, 27 (4) 521-526. http://dx.doi.org/10.1590/S010237722011000400017

Wagner, W. (2015). Representation in action. In G. Sammut, E. Andreouli, G. Gaskell, \& J. Valsiner (Eds.), The Cambridge Handbook of Social Representations (pp. 12-28). Cambridge, UK: Cambridge University Press.

World Health Organization (2002). World report on violence and health. Genebra: Switzerland.

World Health Organization (2006). Preventing child maltreatment: A guide to taking action and generating evidence. Geneva, Switzerland.

Submetido em: 17/12/2019

Aprovado em: 22/07/2020 